\title{
Pensar, repensar e pensar de novo: a música na atualidade
}

E liete Vasconcelos G onçalves

M estre em M úsica, UFRJ

SMERJ/UFR J 


\section{Resumo}

A proposta deste artigo é refletir sobre o significado que a música possui atualmente, partindo do que ela realmente é para o que a imputam. $N$ esse sentido, pensar a partir do próprio significado do fazer musical para trazer à tona os modos atuais sobre o papel que a música tem assumido. A proposta aqui é essencialmente pensar e refletir para então tentar promover uma elucidação particular da forma de lidar com a música, permitindo assim uma auto- avaliação do fazer musical. 0 referencial teórico de suporte está embasado em filósofos e sociólogos do campo da E ducação e E ducação M usical tendo como eixo principal a emancipação humana e na proposta de se pensar a música como meio para realizá-la. 0 trabalho é parte das reflexões apontadas pela autora no desenvolvimento da sua pesquisa de mestrado.

Palavras-chave: M úsica; E ducação; Pensamento.

\section{Abstract}

The purpose of this article is to reflect on the meaning that music currently has from what it really is to what impute it. In this sense think of the very meaning of musical making to bring to light the current modes on the role that music has assumed. The proposal here is essentially to think and reflect and then try to promote a particular elucidation of the way of dealing with music, thus allowing a self-evaluation of musical making. The theoretical framework of support is based on philosophers and sociologists in the field of Education and Music Education, whose main focus is human emancipation and the proposal to think of music as a means to achieve it. The work is part of the reflections pointed out by the author in the development of her masters research.

K eywords: M usic, E ducation, Thought 


\title{
Introdução
}

\author{
Pensar nas formas de se fazer música nos fez refletir sobre a sua utilização na \\ atualidade, assim, iniciamos essa observação a partir de um texto escrito por M ondrian \\ em 1920 e que foi citado por Koellreutter em um artigo:
}

\begin{abstract}
O futuro dirá que haverá um tempo em que seremos capazes de renunciar a todas as artes como as conhecemos hoje; pois então, a beleza, alcançando a maturidade, terá chegado a uma realidade tangível. Quando a consciência humana tiver amadurecido a ponto de que as contradições sejam percebidas dentro de sua unidade complementadora, quando o sentido da vida não mais for considerado trágico, e quando a arte tiver sido total e plenamente integrada na vida, estaremos prontos a dispensar a arte, no seu sentido tradicional, pois nesse tempo futuro, tudo será arte. Então, de modo geral, arte teria universalmente uma utilidade sempre presente e por esta razão não mais seria designada como Arte (p. 37).
\end{abstract}

Se a proposta deste trabalho é clarificar as relações que se estabelecem com a música hoje, a conscientização desses meios de relação nos permitirá alcançar uma maturidade onde renunciar a arte enquanto artefato manipulável será uma premissa para então termos um encontro com o belo enquanto ela se realiza na sua autenticidade ${ }^{1}$.

Em alcançando isso, teremos amadurecido a ponto de viver se constitui como um realizar ${ }^{2}$, em toda a poesia que a palavra "viver" conclama. Que a vida, o existir se estabeleceria de uma maneira que relação seria sinônimo de experiência ${ }^{3}$ e em se experienciar, tornar-se-ia, em se tornar, s eria ${ }^{4}$. Para tal, a arte seria o tudo enquanto a vida acontecesse e, sendo o tudo, não teria necessidade de existir, porque a vida seria a arte, tudo seria arte. Então, desse modo, a sua utilidade se faria como uma necessidade, não como um propósito, mas como uma essência e, sendo essência, já não seria mais arte, seria humano, seria Ser.

\footnotetext{
${ }^{1}$ Fazendo referência ao poema "O futuro dirá que haverá um tempo em que seremos capazes de renunciar a todas as artes como as conhecemos boje"

${ }^{2}$ R eferência ao poema: "pois então, a beleza, al cançando a maturidade, terá chegado a uma realidade tangivel."

3 "Relação seria sinônimo de experiência" - antecipando a parte 3 do texto onde trato da experiência como ato mais complexo que a linguagem que se propõe dar conta dela. Fazendo uma alusão à experiência de vida vivida como de fato precisa acontecer, como vida e não como uma experiência aprisionadora onde as relações são frias e a vida acontece muitas vezes sem sentido, sem se viver.

4 "e em se experienciar, tornar-se ia, em se tornar, seria." O fato de se ter a vida vivida em seu toda sua complexidade, livre das amarras que a sociedade impõe dos pensamentos que transformam muitos em seres minorizados, limitados, diminuídos, transformaria-nos em Seres livres (parte 4 do texto - entre o ser e o tornar-se). Ser - livre, emancipado; aquele que se torna - refém da sociedade capitalista, preso.
} 
Ilusão, ficção, utopia? M as o que seria do mundo sem os vislumbres? 0 que seria da arte sem o enxergar além, ou da música sem a experimentação?

Limitar a música dentro dos parâmetros sociais talvez também pudesse ser pensado como algo irreal; no entanto, de certa forma, acontece.

A relação do humano com a música ocorre de maneiras diversas nas diferentes sociedades. 0 modo de interagir e de fazer música se realiza como um processo dinâmico que acontece diferentemente em tempos e sociedades distintas.

\begin{abstract}
U m novo tipo de sociedade condiciona um novo tipo de arte. Porque a função da arte varia de acordo com as exigências colocadas pela nova sociedade; porque uma nova sociedade é governada por um novo esquema de condições econômicas; e porque mudanças na organização social e, portanto, mudanças nas necessidades objetivas dessa sociedade, resultam em uma função diferente de arte (KOELLREUTTER, 1997, p.37).
\end{abstract}

\title{
A música no hoje
}

A tualmente, vivemos em nossa sociedade uma revolução tecnológica que poderia ser comparada à revolução das máquinas. A pesar de eventos similares, a tecnologia da atualidade não substitui o trabalho físico; em vez disso, passa a atuar em trabalhos não físicos. Enquanto a tecnologia se desenvolve, a relação do humano com a música se reconfigura, ou talvez se desdobre, abrindo novas possibilidades ou suscitando modos já existentes que haviam sido esquecidos.

A revolução tecnológica, bem mais do que substituir fisicamente o humano, penetra em uma realidade mais intrínseca, produzindo novas formas de pensamento.

\footnotetext{
D urante essa fase de desenvolvimento social, a tecnologia penetra na realidade do mundo psico-espiritual do homem, criando novas categorias de pensamento lógico e racional, um acontecimento cujas consequências não podem ser totalmente previstas nos campos social e cultural que estão em processo de civilização (KOELLREUTTER, 1988, p.37).
}

A pesar dessa diferente constituição social em que vivemos, ainda se nota um pensamento conservador musical que atende a uma estrutura social obsoleta dentro do contexto da nossa sociedade contemporânea. 
$\mathrm{Na}$ escola, onde as relações se apresentam como um modelo imitativo de sociedade, todas essas mudanças nas formas de pensar e agir ficam mais evidentes.

Se, por um lado, emerge uma autêntica forma de se experimentar música - vital, estruturante, sensível e humanizadora -, por outro, insiste-se em mantê-la submetida a padrões tão condicionantes quanto possíveis. A rte torna-se 0 fator preponderante de estética e de humanização do processo civilizador, e entender isso se faz necessário para se desprender do jugo ao qual ela é submetida continuamente.

\begin{abstract}
Como um instrumento de liberação, a arte na nova sociedade se torna um meio indispensável de educação, oferecendo uma contribuição essencial à formação do ambiente humano. Assim, através da sua reintegração na sociedade, a arte tornar-se á um traço central da nova sociedade, desde que, por meio desta sua reintegração, ela vença sua alienação social e sobreviva, portanto à sua crise (KO E L LRE UTTER, 1988, p.38-39).
\end{abstract}

Portanto, uma música que sobreviva a esse novo mundo precisa não apenas de uma reformulação adequada de seu ensino, mas de uma real compreensão de seu sentido.

U ma prática atual da escola é supervalorizar a razão em detrimento da emoção. D isciplinas que têm em sua essência a racionalidade são tidas como superiores às que não são tão passíveis de transcrição, o texto em caráter superior à linguagem.

A escola contemporânea, apesar de apresentar todos esses sinais da nova sociedade ainda vive enraizada sob conceitos ultrapassados de educação.

A reforma no ensino, muitas vezes anunciada em forma de novos modelos revolucionários de escola, traz novos títulos, termos e expressões, mas ainda esconde antigos conceitos.

A música, juntamente com a dança, teatro e artes visuais (BRA SIL, 2016), pela atual L ei das Diretrizes e Bases da Educação $N$ acional (LDBEN), é considerada um saber social de referência, sendo integrante do componente curricular do campo das artes, enquanto as demais disciplinas, ditas tradicionais, estão vinculadas às áreas científicas de referência. Dessa forma, a música/arte é tratada com menor valor em relação às demais disciplinas nos documentos de referência escolar, também pelos professores no interior da escola e consequentemente pelos alunos, causando um movimento circular de subvaloração da música. De modo similar, outra maneira de 
diminuir a música em relação às demais disciplinas, segundo Goodson (apud SOBREIRA , 2012) é através da sua força comprovada em relação ao conteúdo exigido nos exames acadêmicos, como os do $E$ xame $N$ acional do $E$ nsino $M$ édio (ENEM).

I gualmente à música, outras disciplinas que também não possuem uma ciência como saber de referência recebem o mesmo trato de baixo status, como a Educação Física, por exemplo, que tem sua função escolar reduzida ao papel de disciplinar os corpos e comportamentos.

$\mathrm{N}$ ecessitando de uma justificativa que valide a presença da música no espaço escolar, o senso comum/sociedade atribuiu à sua função características extrínsecas ao seu valor, tais como: lazer e a socialização; ser coadjuvante no aprendizado de alguma disciplina tradicional como para desenvolver o raciocínio matemático ou auxiliar na concentração; efeitos terapêuticos enquanto utilizada para acalmar.

A escola atual, que em sua mai oria contempla um ensino puramente acadêmico e destituído da realidade, procura afastar do humano tudo que é referente à sua espontaneidade, distanciando a música do prazer que ela proporciona e de seu caráter expressivo. Essa mesma escola que subjuga a música tenta Ihe imputar funções que dizem Ihe valorar, como se valorizando seus efeitos, justificasse a sua utilização.

Essa posição de subvaloração ou baixo status que a música ocupa dentro das escolas, ora pertencendo ao currículo obrigatório, ora não, diante das constantes mudanças das diretrizes que regem a educação brasileira, ocasiona que os mesmos padrões que norteiam as orientações curriculares impostas aos professores das demais disciplinas, no caso da música, sejam ausentes. A pesar de essa ausência poder explicitar a falta de significância da música ao lado das demais disciplinas, também favorece uma maior liberdade ao professor, que tem total autonomia sobre o conteúdo a ser ensinado e como lecioná-lo. Assim, apesar de estar em um ambiente rígido e disciplinador, a música dentro da escola encontra caminho livre nas mãos do professor para se adequar às realidades daquele meio social em que está inserida, às características regionais em que se encontra e às suas escolhas pedagógicas.

$E$, nessa constituição das identidades, as disciplinas que são racionalmente ensinadas e aprendidas são suficientes apenas para criar sujeitos reprodutores do mesmo sistema.

Se, desse modo, o sujeito precisa dedicar anos de vida aos estudos letrados, e isso o faz competente naquilo que escolheu para trabalhar, por outro lado, essa ação de 
profissionalizar cada vez mais indivíduos, fragmentados e especialistas em conceitos que acabam por retirar ou expulsar suas diversas sensibilidades, pode ter suas consequências.

É necessário que se desvele um ensino musical em que a música possa "acontecer" e, acontecendo, ela possa se fazer "ser" no indivíduo. Uma educação musical capaz de transformar critérios e ideias artísticas em nova realidade deve partir da consciência do professor de música. U ma educação musical que liberta deve ser livre em transparecer como instrumento de progresso, transformação da personalidade, estímulo à criatividade e emanci pação.

\section{Entre a experiência e a linguagem}

A lgo que se torna secundário em toda essa discussão a respeito do que é mais ou menos importante é a experiência, o encontro do indivíduo com aquela linguagem, uma experiência que não é traduzível. A experiência é sempre mais complexa que a linguagem que se propõe a dar conta dela. Q uando se resume a matemática, a geografia, o português a um conteúdo frio, traçado, delimitado em regras e valores e despreza-se muitas vezes a sua experiência, limita-se 0 aprender pelo entender e pelo executar, e determinados conteúdos são mais suscetíveis a essa transformação.

Quando se fala das artes, ou da música em específico, como traduzir a experiência em conceitos ou como desvincular uma coisa da outra? Como traduzir a experiência de aprendizado musical e determinar fórmulas para o seu acontecer?

Se a escola determina que os alunos devam aprender conteúdos, como enumerar, nomear, descrever e delimitar algumas experiências musicais? Será que isso é um fator negativo? Será que isso é só uma característica das artes? 0 u será uma condição?

T orna-se necessário perceber que essa é uma condição da experiência e, só assim, aprender a lidar com esses saberes, que, por vezes, não podem ser descritos por palavras ou determinados como certos ou errados. T ambém se torna necessário compreender que cada experiência se traduz de uma forma para o mundo, que a ciência não é a única forma de se traduzir a experiência do mundo e nem necessariamente a melhor. $\mathrm{N}$ ão existem formas superiores ou inferiores; existem traduções diferentes para linguagens diferentes. 
Essa racionalidade moderna induz-nos a acreditar que há uma relação muito forte entre a ação e o conhecimento. É a razão iluminista fundamental que diz que, quanto mais e melhor o sujeito conhece o mundo, mais e melhor ele age também.

0 mundo moderno trouxe ao sujeito um sentimento estável do seu próprio eu. Torna-se autônomo, independente, ciente de si e que reflete e interage com o mundo racional. Posteriormente, $\mathrm{M}$ arx, $\mathrm{N}$ ietzsche, juntamente com todo desdobramento da psicanálise, bem como Foucault, promovem uma reflexão e desconstrução dessa razão iluminista - o sujeito não age pela razão ou pelo conhecimento; ele age pela emoção, pela paixão. 0 que move 0 sujeito é muito maior que um imperativo ético ou epistemológico, o que não quer dizer que o conhecimento não seja algo fundamental. Pode-se assim pensar em uma razão e sensibilidade que se expresse em nossas experiências. A razão e a emoção precisam caminhar lado a lado, uma não invalidando ou se sobrepondo à outra.

\section{Música e a reconstrução do ser}

"O "ser" e o "tornar-se" tomam forma na expressão musical.

Inconsciente de sua estagnação social delineada pelo assujeitamento e desumanização que o capitalismo e as outras formas de normalização impuseram, a música é capaz de transfigurar o sujeito oprimido, permitindo que ele se veja em seu contexto e se humanize.

T al qual a pedagogia transformadora que $\mathrm{F}$ reire ${ }^{5}$ propôs, uma educação capaz de libertar-se de conceitos rígidos e condicionantes e que atua entre opressores e oprimidos sustenta-se na humanização de indivíduos. U ma humanização que não só reconstrói a consciência, mas que também gera um engajamento na luta pela sua libertação.

\footnotetext{
${ }_{5}$ Paulo Freire foi um educador, pedagogista e filósofo brasileiro. É Patrono da Educação Brasileira, sendo considerado um dos pensadores mais notáveis da história da Pedagogia mundial, tendo influenciado o movimento chamado pedagogia crítica. A sua prática didática fundamentava-se na crença de que o educando assimilaria o objeto de estudo fazendo uso de uma prática dialética com a realidade, em contraposição à por ele denominada educação bancária, tecnicista e alienante: 0 educando criaria sua própria educação, fazendo ele próprio o caminho, e não seguindo um já previamente construído; libertando-se de chavões alienantes, o educando seguiria e criaria o rumo do seu aprendizado. Seu trabalho se destacou na área da educação popular, voltada tanto para a escolarização, como para a formação da consciência política (FE R RA RI, 2017).
} 
Os caminhos trilhados pela educação no decorrer dos séculos, em sucessivos recortes, fragmentações e reconfigurações, encontram em Freire uma proposta reversa, um caminho contrário que busca um humano consciente e formado em todas as suas capacidades, emancipado.

E ssa desumanização histórica que se contrapõe ao ideal emancipatório encontra racionalidade iluminista enquanto pretende alcançar um sujeito crítico, que seja capaz de libertar-se das opressões da realidade social injusta causada pelo capitalismo.

\begin{abstract}
A relação que há em F reire entre autonomia e libertação já ocorria no iluminismo, no entanto, o educador brasileiro propõe a libertação em relação às opressões da realidade social injusta causada pelo sistema capitalista, já os iluministas propunham a libertação em relação às opressões causadas pela tradição, pela religião e pelo A ntigo Regime. T anto para os iluministas quanto para F reire, cabe à educação formar um sujeito crítico, que enquanto tal seja capaz de se libertar, se emancipar da condição de menoridade. N esse sentido Paulo Freire é herdeiro do iluminismo. (ZAT TI, 2007, p. 64).
\end{abstract}

Tal qual as ideias de Kant (1985) na sua resposta ao que é Esclarecimento (Aufklärung), F reire propõe um sujeito que se liberte dos condicionamentos sociais, seja autônomo, que saiba exprimir juízos. No entanto, difere-se quando sustenta a necessidade de formar o indivíduo que exerça uma postura de autorreflexão e de reflexão sobre seu tempo e espaço. Para formar esse sujeito, é necessário não só a sua própria reflexão, seu próprio entendimento, mas será preciso devolver a esse humano as características que Ihe são fundamentais, a humanidade. U ma emancipação autêntica se promove através de um esclarecimento, mas se constrói sobre uma relação respeitadora do humano como pessoa, no seu sentido ontológico. N esse sentido, Freire se aproxima do ideal de educação da Paideia grega, quanto expressa que, para formar esse humano emancipado, a racionalidade não basta, é necessário resgatar a humanidade, e isso só acontece através do desenvolvimento de todas as capacidades do indivíduo; isso inclui não só a razão, mas também a emoção.

D essa maneira, esse tipo de educação se refaz constantemente na sua práxis. Para ser, tem que estar sendo, se construindo, se reconstruindo (FREIRE , 2005).

A essência do humano está em uma constante construção, em um constante processo de se ser e de se fazer. Ele é o que ele faz de si; ele é o que se projeta para ser, e impedir ou interferir de forma a contrariar essa essência impulsiva do humano é injusto. 
A música permite ao humano a reestruturação do seu "eu", permite lidar com o desconhecido, tal como a arte, que sempre foi uma função estruturante da consciência (DINIZ, 2009).

Pensar em um humano consciente de seu lugar social, reflexivo e atuante é uma proposta que permite reestruturar todos os caminhos que a educação trilhou. A ntes disso, permite refazer, refletir, questionar e humanizar.

A ssim, necessita-se dessa teoria humanista que vem contestar as relações entre as pessoas, seguindo esse papel de subordinação, estruturado por uma sociedade opressora que se delineou. Um estado de luta através do esclarecimento, da conscientização, da utilização/aplicação do conhecimento para uma libertação.

Pensar essa educação que contraria as normalidades impostas pela escola disciplinadora é pensar em um caminho de transformação, de ir contra, de caos, de incertezas, mas de mudanças, de reflexões, de tentativas, de erros e acertos, tal qual G allo (2007) propôs:

Precisamos ter a coragem de rasgar o falso céu deste mundo artificial e mergulhar no caos, por mais estranho, feio e assustador que ele possa parecer. Fazer a experiência do estranhamento, do perder-se de si mesmo, do mergulho na multiplicidade, longe de hierarquias, certezas, controles; abrir-se para as delícias do desconhecido, ter a coragem de ousar. T rês potências nos ajudam nessa aventura: as artes, as ciências e as filosofias. Porque as três, cada uma a sua maneira, vencem a opinião e mergulham no caos, trazendo do contato com ele novas possibilidades (p.10).

U ma pedagogia que vai além da simples normatização, das simples sugestões que nos são oferecidas como propostas de se mudar o mundo e resolver os problemas da sociedade, do currículo novo, do novo modelo de escola, das novas atitudes propostas pela escola velha, que, na verdade, apenas mascaram um velho jeito de ensinar com novas nomenclaturas. U ma pedagogia que transforma de dentro, que refaz o olhar que se tem sobre si mesmo e sobre o outro, que não só se afasta do individualismo, mas reflete sobre ele.

Jung ${ }^{6}$ fala sobre a humanização enquanto poder transformador, tal qual F reire,

\footnotetext{
${ }^{6} \mathrm{C}$ arl G ustav Jung foi um dos maiores estudiosos da vida interior do homem. Foi um psiquiatra suíço, fundador da escola da Psicologia A nalítica. D esenvolveu os conceitos da personalidade extrovertida e introvertida, de arquétipos e do inconsciente coletivo. Para Jung, imagem é psique. Sua visão de mundo reconhece o poder da imaginação e das representações criativas. Pode-se dizer que ele dedicou sua vida aos sonhos, imagens e visões conferindo a estas um papel estruturante e curativo. Em 1922, Jung escreve sobre a relação da psicologia analítica com a obra de arte
} 
como necessidade, e aponta a arte como parte desse processo. A través da música, é possível tornar visível àquilo que nos é apenas simbólico. A música nos permite exteriorizar sentimentos, emoções, angústias, expressar aquilo que nos atormenta, trazer à consciência, ao mundo real, o que está no mais profundo no nosso inconsciente.

H umanizar é a pedagogia; aprender e ensinar são um caminho.

$N$ essa reflexão entre 0 aprender e 0 ensinar, Freire nos permite reconfigurar a compreensão da essência do ensino, retornando ao sentido mais primordial da educação: foi aprendendo socialmente que, historicamente, mulheres e homens descobriram que era possível ensinar. [...] A prender precedeu ensinar ou, em outras palavras, ensinar se diluía na experiência realmente fundante de aprender (FREIRE, 2010, p. 23-24). E nsinar não é transferir conhecimento, mas criar as possibilidades para a sua produção ou a sua construção (FREIRE, 2010, p. 22).

F reire nos sugere pensar uma pedagogia que busque a construção de um sujeito autônomo, que pensa certo, não só logicamente, mas eticamente. U ma autonomia que também se relaciona a pensar um sujeito ciente de sua posição social, não egocêntrica, mas que, entendedor do seu papel, possa saber se relacionar com o outro de forma a configurar espaços equilibrados de relacionamento.

É essa fundamentação ético-antropológica que permite pensar um indivíduo que pretende ser em vez do tornar-se, que impossibilita uma separação entre o Ser e o deverser, onde a razão e a liberdade se constituem no humano como categorias que não podem ser dissociadas.

M ulheres e homens, seres histórico-sociais, nos tornamos capazes de
comparar, de valorar, de intervir, de escolher, de decidir, de romper,
por tudo isso, nos fizemos seres éticos. Só somos porque estamos
sendo. Estar sendo é a condição, entre nós, para ser. Não é possível
pensar os seres humanos longe, sequer, da ética, quanto mais fora dela.
Estar longe ou pior, fora da ética, entre nós, mulheres e homens é uma
transgressão. É por isso que transformar a experiência em puro
treinamento técnico é amesquinhar o que há de fundamentalmente
humano no exerćcio educativo: o seu caráter formador. Se se respeita

poética. Ele discorre sobre o processo de criação artística, como uma atividade psicológica e como tal objeto da psicologia. Para ele "o que é a arte em si, não pode ser objeto de considerações psicológicas, mas apenas estéticoartísticas" (JUNG, 2012, p. 65). O autor considera a obra de arte em estado nascente um complexo autônomo, algo suprapessoal "poderíamos até falar de um ser que utiliza o homem e suas disposiçóes pessoais apenas como solo nutritivo, cujas forças ordena conforme suas próprias leis, configurando-se a si mesma de acordo com o que pretende ser." (JUNG, 2012, p. 72). O momento de criação é uma realização criativa da psique objetiva e os questionamentos devem buscar o sentido da obra de arte. 
a natureza do ser humano, o ensino dos conteúdos não pode dar-se alheio à formação moral do educando. Educar é substantivamente formar. Divinizar ou diabolizar a tecnologia ou a ciência é uma forma altamente negativa e perigosa de pensar errado (FRE IRE , 2010, p.33). Ademais, é reconhecer a finitude humana, no seu condicionamento e inacabamento para se pensar uma educação formadora tanto no âmbito do conhecimento quanto da ética. Considerar que estamos continuamente em uma construção histórica, que somos um projeto em constante transformação e, por assim dizer, inacabado, reforça essa não conformação com determinado condicionamento histórico.

O nde há vida, há inacabamento. $M$ as só entre mulheres e homens 0 inacabamento se tornou consciente. A invenção da existência a partir dos materiais que a vida oferecia levou homens e mulheres a promover 0 suporte em que os outros animais continuam em mundo. Seu mundo, mundo dos homens e das mulheres. A experiência humana no mundo muda de qualidade com relação à vida animal no suporte. (FREIRE , 2010, p. 50).

A capacidade moral e cognitiva do humano demonstra seu inacabamento. Conhecendo, decidindo e se interpondo, ele constrói seu mundo na história. D entro desse seu atributo de se autoconstruir e construir-se historicamente, ele enfrenta-se com os próprios condicionamentos históricos que se encontra. É esse desejo de Ser mais que exige a superação daquilo que se é.

$\mathrm{G}$ osto de ser gente porque a $\mathrm{H}$ istória em que me faço com os outros e de cuja feitura tomo parte é um tempo de possibilidades e não de determinismo. Daí que insista tanto na problematização do futuro e recuse sua inexorabilidade. [...] G osto de ser gente porque, inacabado, sei que sou um ser condicionado mas, consciente do inacabamento, sei que posso ir mais além dele. Esta é a diferença profunda entre 0 ser condicionado e $o$ ser determinado. (FREIRE, 2010, p. 53).

D esde os tempos mais remotos, buscamos ser mais. E ssa natureza inventiva do ser humano é natural e está presente desde sempre nas suas manifestações. É uma necessidade ontológica que temos para superar o condicionamento histórico no qual nos encontramos. Ser inacabado explica essa necessidade de busca, de superação dessas dificuldades concretas de nossa existência. "Conscientização" foi o termo utilizado por 
F reire para nomear essa busca incessante do indivíduo por ser mais, ter consciência da sua inconclusão.

\begin{abstract}
A consciência do mundo e a consciência de si como ser inacabado necessariamente inscrevem 0 ser consciente de sua inconclusão num permanente movimento de busca. $\mathrm{N}$ a verdade, seria uma contradição se, inacabado e consciente do inacabamento, o ser humano não se inserisse em tal movimento. É neste sentido que, para mulheres e homens, estar no mundo necessariamente significa estar com o mundo e com os outros. (FREIRE, 2010, p. 57).
\end{abstract}

Essa proposta de educação que não se atém às pedagogias teóricas e estáticas, mas que lida com um conceito mais amplo do que o de formação do indivíduo e que mais se relaciona com os conceitos gregos de Paideia, parte da conscientização de um ser que toma consciência do seu inacabamento e, assim, tem, através dela, a sua principal função, que é formar-se. Portanto, uma educação que lida com um indivíduo completo, complexo e livre é uma proposta de educação que está além de nosso tempo, além de uma sociedade marcada pela opressão das classes dominantes e capitalistas.

Quando Ivan Illich (1985) propôs uma sociedade sem escolas, talvez ele propusesse não uma desconstrução do ensino escolarizado, mas uma desconstrução do modelo tradicional de ensino nos moldes que nos são impostos, que nos são vendidos como verdadeiros e competentes ou, mais que isso, uma reconstrução daquilo que pensamos como educação ou escolarização.

Diferentes formas de ensinar são propostas em diversas partes do mundo e exprimem a sua eficácia. $\mathrm{Nem}$ precisamos ir tão longe. A qui no Brasil mesmo os exemplos são diversos: o C entro Popular de C ultura e D esenvolvimento (CPCD), em B elo $\mathrm{H}$ orizonte, $\mathrm{M}$ inas $\mathrm{G}$ erais, que propõe um aluno protagonista e um ensino lúdico e livre em uma reformulação na forma de ensinar e lidar com os conteúdos; a Escola Politeia, em São Paulo, que estimula o contato dos alunos das diferentes idades, cada qual contribuindo e se desenvolvendo em contato com o todo, bem como os valores democráticos e éticos priorizados na formação do aluno enquanto um cidadão político; ou a E scola V iva I nkiri, localizada em Piracanga, na Bahia, que reforça a importância da criatividade e tem como base os princípios espirituais do ser humano que surge como proposta a uma transformação interna e a valorização da liberdade de escolha (RA SM USSE M , 2017). 
Esses modelos, mais do que surgirem como referências de ensino, nos servem para mostrar que o conceito de emancipação é muito amplo. Vai além de um pensar por mim, pois, enquanto eu me emancipo, eu promovo, eu realizo. E mancipação contribui sim para um desenvolvimento meu, mas que uma emancipação social pode promover muito mais por mim, e que o todo é maior, sempre. E mancipar é um verbo dinâmico, que exige ação, que pode se construir na singularidade, mas que se realiza na sua generalidade. Um indivíduo emancipado é um indivíduo político, ativo, propositivo. A escola que temos hoje é produto de uma construção histórica e, assim, só faz sentido dentro de sua historicidade. Portanto, emancipar é fazer um novo modelo de escola, sem escola.

Um indivíduo liberto, emancipado e completo é a luta mais eficaz para se combater esse determinismo limitante que tende a aprisionar para dominar, desprovendo- 0 de sua essência.

T al qual a música, o mundo quer limitar o ser, quer subjugar, quer diminuir para limitar suas capacidades. No entanto, e tal qual ela, o humano se liberta, pois o que possui dentro de si é mais forte que as amarras que pretendem reprimi-lo.

A emancipação humana é um conceito que atravessa as gerações, suscitada por diversos filósofos para nomear essa atitude de liberdade que prende alguns. Sim, prende alguns, mas não todos, e os que não se permitem prender se imbricam nessa missão de desatar os demais.

0 processo é difícil, árduo e precisa ser contínuo, mas não faltam nomes que se concentraram nessa tarefa de multiplicar o esclarecimento: filósofos, sociólogos, psicólogos, educadores, parte deles aqui relatados numa busca de se refletir sobre os fragmentos da vida moderna e tentar realinhar aquilo que não pode ou não deve ser fragmentado: a essência da vida, o humano e a música.

\section{Considerações finais}

Pensar, repensar e pensar de novo é a proposta feita aqui. A música que produzimos e realizamos dia após dia cria significados diferentes a partir da maneira como é compreendida, realizada. D essa forma, nos afastar desse objeto - música permite-nos tentar entender como a temos realizado atualmente. E nquando educadores, 
temos nos submetido ao lugar em que a sociedade nos coloca? Como temos feito música, como temos realizado e como a temos compreendido?

A ideia aqui não é trazer respostas, mas propor pensamentos e assim essa ideia não se finda no seu concluir, mas no seu itinerário.

$\mathrm{N}$ ão é na repetição sistemática do princípio que temos a sua realização, mas na sua reflexão; dessa forma, pensar, repensar e pensar de novo para então produzir mudanças e novamente mudanças, a cada etapa, em suas inconclusões.

A música e a forma de se lidar com ela dentro da escola foi o ponto de partida. 0 espaço escolar tradicional com todos os seus mecanismos normalizadores é um lugar em que o fazer musical se faz necessário; no entanto, o professor de música também deve estar atento para não reproduzir através dela esses mesmos mecanismos. Entender que a música cria significado no humano em sua realização permite compreender que observar a realidade social desse aluno pode facilitar a construção de um significado em torno desse fazer. As mudanças ocasionadas na nossa sociedade atual e toda a sua tecnologia fazem emergir novas formas de se fazer música, e estar sensível a essas inovações pode suscitar novas formas de se experimentar música, entendendo que cada humano tem uma maneira diferente de se relacionar com os saberes e que a experiência que cada um realiza com a música pode ter significados e ser absorvida se modos distintos para cada um que a realiza.

Para o músico, professor de música, um grande passo a ser dado é entender que não existem necessidades de se justificar o fazer musical; que reduzi-lo a uma serventia, aplicabilidade ou propósito é diminuir demais o seu valor; que o aprendizado de um instrumento serve para aprender a tocar um instrumento e que o seu valor acontece entre a essência desses dois objetos: o humano e a música; que ouvir música serve para ouvir música, pelo prazer, e que sentir prazer é um direito de todos; que contemplar 0 belo é uma necessidade humana; e que realizar arte é natural, é trazer de dentro aquilo que está oculto, é fazer emergir.

A maneira como os professores interagem entre si e com os alunos contribui para reforçar essa experiência simbólica e valoriza a importância desse prazer estético sem que isso seja necessário se justificar.

Portanto, ambicionar um mundo onde a arte seja tudo e tudo seja arte sem a necessidade de se objetificá-la é um pensamento possível; talvez utópico, mas possível. 
O utópico não é o irrealizável; a utopia não é o idealismo, é a dialetização dos atos de denunciar e anunciar, 0 ato de denunciar a estrutura desumanizante e de anunciar a estrutura humanizante. Por esta razão a utopia é também um compromisso histórico (FREIRE, 1980, p. 27).

Portanto, nos amparamos nessas palavras, ao desvelar a funcionalização, a normalização, a disciplinarização e a desumanização, concluindo que ter a música se realizando no indivíduo livre das legitimações que lhe são impostas é um passo, mas têIa plena, realizada e se realizando circularmente e ininterruptamente pelo humano, como natural em natureza, é uma possibilidade real na sociedade, mas ainda na escola.

\section{Referências}

BRA SI L . L ei das diretrizes e bases da educação nadional. L ei número 13.278, 2 de maio de 2016. D isponível em:

বttp://www.planalto.gov.br/ccivil_03/_ato2015-2018/2016/lei/l13278.htm>. A cessado em 2 de outubro de 2017.

DIN IZ, L . A rte: L inguagem da alma. In: M O NTE IRO , D. M . (org) Arteterapia e Símbolos. Rio de Janeiro: W ak E ditora, 2009, p.21-43.

FERRARI, M árcio. Paulo F reire, o mentor da educação para a consciência. D isponível em: <https://novaescola.org.br/conteudo/460/mentor-educacao- consciencia>. A cessado em 4 de outubro de 2017.

FRE IRE , Paulo. Conscientização: T eoria e P rática da L ibertação - U ma introdução ao pensamento de Paulo Freire. São Paulo: M oraes, 1980.

. Pedagogia da Autonomia: saberes necessários à prática educativa. 41a reimpressão. São Paulo: Paz e T erra, 2010. . Pedagogia do oprimido. Rio de Janeiro: Paz e T erra, 2005.

IL L IC H , I van. Sociedade sem escolas: trad. de L úcia M athilde E ndlich O rth. P etrópolis, V ozes, 1985. 
JU N G , C arl G ustav. Relação da psicologia analítica com a obra de arte poética. In: 0 espírito na arteena dência. 7. E d.; Petrópolis: E ditora V ozes, 2012.

KAN T, I mmanuel. T extos seletos. O rg. C arneiro L eão, E. Petrópolis: V ozes, 1985.

KOELLREUTTER, H ans-J oachim. 0 ensino da música num mundo modificado. In: C adernos de estudo: educação musical. $\mathrm{O}$ rg. C arlos $\mathrm{K}$ ater. Belo H orizonte: A travez/EM UFM G/FEA/FA PE M IG , 1997.

RA SM USSE M , B runa. E ducação fora da caixa: conheça escolas onde 0 aprendizado vai muito além da lousa ou do caderno. D isponível em: < http://www.hypeness.com.br/2015/01/como-iniciativas-de-educacao-inovadorasbuscam-transformar-o-ensino-no-brasil/>. A cessado em 02 de outubro de 2017.

SO BREIRA, S. A disciplinarização do ensino de M úsica e as contingências do meio escolar. Per M usi, Belo H orizonte, n.26, 2012, p.121-127.

ZATTI, V icente. Autonomia eE ducação em I mmanuel K ant ePaulo F rére. Porto A legre: E dipucrs, 2007. 